\title{
Interactions Between Monetary and Fiscal Policy Under Flexible Exchange Rates ${ }^{1}$
}

\author{
Campbell Leith* \\ Simon Wren-Lewis**
}

*University of Glasgow
**University of Exeter

\begin{abstract}
We extend the fiscal theory of the price level (FTPL) by developing a two-country openeconomy model under flexible exchange rates, where overlapping generations of consumers supply labour to imperfectly competitive firms which change their prices infrequently. We show that the fiscal response required to support an active inflation-targeting monetary policy is greater when consumers have finite lives. Additionally, one monetary authority can abandon its active targeting of inflation to stabilise the debt of a fiscal authority, even if the policy makers operate in different countries. Finally, through simulations, we consider the impact of fiscal shocks on key macroeconomic variables.
\end{abstract}

JEL codes:E10, E63.

Keywords: Monetary Policy, Fiscal Policy, New Open Economy Macroeconomics, Fiscal Theory of the Price Level.

Word Count: 7230

Address for correspondence:

C. B. Leith,

Department of Economics, University of Glasgow, Adam Smith Building, Glasgow G12 8RT E-Mail: C.B.Leith@socsci.gla.ac.uk

\footnotetext{
${ }^{1}$ We are grateful to the ESRC for the financial support (Grant No. L138251050) which enabled us to undertake this research. We are also grateful to Massimiliano Rigon for helpful comments on an earlier draft of the paper. All errors remain our own.
} 


\section{Introduction}

Following Woodford (1995) a literature has developed under the heading of the 'Fiscal Theory of the Price Level' ${ }^{2}$. Under certain conditions ${ }^{3}$ the economy is in one of two regimes - a 'Ricardian' regime where the fiscal authorities act prudently, government debt does not constitute an element of net wealth and monetary policy is free to target inflation, and another, 'non-Ricardian' regime, where fiscal insolvency requires surprise inflation to deflate the nominal value of government debt, irrespective of the stance of monetary policy. In earlier work (Leith and Wren-Lewis (2000)) we relaxed a number of assumptions underlying the FTPL, by considering a closed economy with overlapping generations of consumers supplying labour to imperfectly competitive firms which could only adjust their prices infrequently. This economy also had two stable policy regimes: one where the fiscal authorities stabilised their debt stocks and monetary policy was active (using the terminology of Leeper (1991)), such that the authorities raised real interest rates when inflation was above target, and another where fiscal instability forced the monetary authorities to react 'passively' to inflation by not raising real interest rates. However both monetary and fiscal policy affected inflation under both regimes, and, additionally, both regimes could occur even if all government debt was indexed.

The FTPL has also been extended to two country, open economy models in the case of both fixed ${ }^{4}$ and flexible exchange rates. Dupor (2000), Daniel (2001) and Loyo (1998) consider the fiscal theory in the context of two open economies, trading a single good and operating under flexible exchange rates, and seek to address the question as to whether or not the FTPL can deliver a determinate nominal exchange rate and price levels in the two economies. Dupor (op. cit.) and Loyo (op. cit.) both find that, by allowing one government to run a no-Ponzi scheme against the other, there is effectively only one equilibrium budget constraint, which is the aggregate of the individual governments' budget constraints. There are, therefore, insufficient equilibrium conditions to define the two price levels and the nominal exchange rate between the two economies as part of a non-Ricardian regime. As noted by Canzoneri et al (2001), if governments are not permitted to run such schemes then

\footnotetext{
${ }^{2}$ For a comprehensive survey of the FTPL see Christiano and Fitzgerald (2000) or Woodford (2001).

${ }^{3}$ The Fiscal Theory assumes that the real level of tax revenues and spending are exogenous such that the fiscal authorities do not adjust real surpluses to ensure their budget constraint is satisfied in the face of negative fiscal shocks. It is also assumed that all real seigniorage revenues are repaid to consumers. The description of the economy is completed with the introduction of an infinitely lived yeoman farmer and as a result the ex ante real interest rate is identical to the representative agent's rate of time preference, and is unaffected by monetary and fiscal policy. Under these conditions, the government's finances are insulated from the effects of monetary policy and, when prices are flexible, the price level adjusts to satisfy the government's budget constraint.
} 
essentially each authority faces their own intertemporal budget constraint, which can either be satisfied by adjusting tax revenues and government spending in the usual way with monetary policy then determining inflation, or through surprise inflation driving a wedge between $e x$ ante and ex post real interest rate as in the FTPL. In either case, prices in both economies are determined and the exchange rate is then tied down by the usual PPP condition

In this paper, section 1 develops a two country open economy model, where - unlike the $\mathrm{FTPL}^{5}$ - each country has overlapping generations of consumers who supply labour to imperfectly competitive firms which can only change their prices infrequently. Consumers in each country purchase differentiated goods produced both at home and abroad. We examine the case where the two countries operate under a flexible exchange rate with independent monetary and fiscal policies. Section 2 analyses the restrictions on monetary and fiscal policy necessary to reach a unique saddlepath-stable rational expectations solution which does not involve indefinite transfers of wealth from the consumers of one economy to the consumers of the other. Section 3 then calibrates the model and compares the macroeconomic consequences of a fiscal shock under the various policy regimes identified in section 2. Section 4 concludes.

\section{$\underline{\text { 1.A Two-Country Model under flexible exchange rates. }}$}

\section{The Consumer's Problem:}

A typical home consumer, i, consumes from a basket of consumption goods, derives utility from real money balances and leisure. The consumer also faces a constant, instantaneous probability of death, $k$, which allows us to write the consumer's certainty equivalent utility function as,

$$
E_{t} U_{t}^{i}=\int_{t}^{\infty}\left[\ln \left(c_{s}^{i}\right)+\chi \ln \left(\frac{M_{s}^{i}}{P_{s}}\right)+\kappa \ln \left(1-N_{s}^{i}\right)\right] \exp (-(\sigma+k)(s-t)) d s
$$

where $\sigma$ is the individual's rate of time preference and the basket of consumption goods is defined by the following CES index applied across home and foreign goods,

$$
c_{s}^{i}=\left[\int_{0}^{1} c_{s}^{i}(z)^{\frac{\theta-1}{\theta}} d z\right]^{\frac{\theta}{\theta-1}}
$$

Similarly, the consumer price index is given by,

\footnotetext{
${ }^{4}$ Woodford (1998), Bergin (2000), Sims (1999) and Leith and Wren-Lewis (2001) consider the case of open economies which have entered into a monetary union with a fixed nominal exchange rate and common monetary policy, but which still operate independent fiscal policies.

5 Woodford (1998), also relaxes the assumption of flexible prices in a closed economy model, but retains the assumption of infinitely lived consumers.
} 


$$
P_{s}=\left[\int_{0}^{1} p(z)^{1-\theta} d z\right]^{\frac{1}{1-\theta}}
$$

Since there are assumed to be no impediments to trade, the law of one price holds for each individual good, so that the home price index can be re-written as,

$$
P_{s}=\left[\int_{0}^{n} p_{s}(z)^{1-\theta} d z+\int_{n}^{1}\left(\varepsilon_{s} p_{s}^{*}(z)\right)^{1-\theta} d z\right]^{\frac{1}{1-\theta}}
$$

where $p(z)$ is the home currency price of $\operatorname{good} z, p^{*}(z)$ is the foreign currency price of good $z$ and $\varepsilon$ is the nominal exchange.

The consumer can hold her financial wealth in the form of domestic government bonds, $D$, foreign bonds, $F$, and money balances, $M$. Due to international arbitrage, domestic and foreign bonds earn the same nominal return, $R$, while domestic consumers receive a share in the profits of domestic firms, $\Pi$. It is assumed that the consumer receives a premium from perfectly competitive insurance companies in return for their financial assets should they die. This effectively raises the rate of return from holding financial assets by $k$. Consumer's pay lump sum taxation of $\tau$. The consumer's budget constraint, in real terms, is given by,

$$
\begin{aligned}
d a_{t}^{i} & =\left(r_{t}-\lambda\left(\pi_{t}-\pi_{t}^{e}\right)+k\right)\left(a_{t}^{i}-m_{t}^{i}-f_{t}^{i}\right)+\left(r_{t}^{*}+k-\lambda^{*}\left(\pi_{t}^{*}-\pi_{t}^{* e}\right)\right) f_{t}^{*_{i}} \\
& +\left(k-\pi_{t}\right) m_{t}^{i}+w_{t} N_{t}^{i}+\frac{\Pi_{t}}{P_{t}}-\tau_{t}-c_{t}^{i}
\end{aligned}
$$

where $a_{t}^{i}$ represents consumer i's financial assets, which can either be held as domestic bonds, as money, $m_{t}^{i}$ or in the form of foreign bonds, $f_{t}^{*_{i}}$. Since PPP holds at all points in time, the ex ante real rates of return on domestic and foreign bonds will be the same, such that $r_{t}=r_{t}^{*}$.

The parameter $\lambda$ measures the proportion of domestic debt which is nominal, and $\lambda^{*}$ measures the extent to which foreign debt is unindexed ${ }^{6}$. It is only to the extent that interestbearing financial wealth is nominal that surprise inflation can erode the real value of financial wealth by decreasing the ex post real interest rate relative to the ex ante rate as under the FTPL $^{7}$. However, in the presence of non-Ricardian consumers and nominal inertia, monetary and fiscal policy jointly determine the ex ante real rate, and this can also affect the evolution of real government liabilities even if debt is indexed.

\footnotetext{
${ }^{6}$ These proportions are assumed to be identical across all home consumers and all foreign consumers, such that they also represent the proportion of each governments' bonds which are denominated in nominal terms.

${ }^{7}$ In our open economy mode, the surprise inflation applicable to debt denominated in foreign currency is foreign consumer price inflation - this captures the loss in return to home consumers arising from surprise consumer price inflation in the home economy and any unexpected appreciation of the nominal exchange rate.
} 
The consumer than has to maximise utility (1), subject to her budget constraint (5) along with the usual solvency conditions. The various first order conditions this implies are given below. Firstly, there is the usual consumption Euler equation,

$$
d c_{t}^{i}=\left(r_{t}-\sigma\right) c_{t}^{i}
$$

The optimisation also yields a money demand equation,

$$
\frac{M_{t}^{i}}{P_{t}}=\chi \frac{c_{t}^{i}}{R_{t}}
$$

and the individual's optimal labour supply decision will satisfy,

$$
\frac{W_{t}}{P_{t}}\left(1-N_{t}^{i}\right)=\kappa c_{t}^{i}
$$

If we normalise total population size to one, then it is possible to aggregate across generations by noting that the current size of a generation of size $\mathrm{k}$ when born at time $\mathrm{z}$ is $k \exp (k(z-t))$. Then aggregate consumption is given by,

$$
c_{t}=\int_{-\infty}^{t} c_{t}^{i} k \exp (k(i-t)) d i
$$

Applying this aggregation to all variables allows us to derive the aggregate domestic consumption function as,

$$
c_{t}=(k+\sigma)\left(\frac{A_{t}}{P_{t}}+\int_{t}^{\infty}\left(\frac{W_{s}}{P_{s}} N_{s}+\frac{\Pi_{s}}{P_{s}}-\tau_{s}\right) \exp \left(-\int_{t}^{s}\left(r_{\mu}+k\right) d \mu\right) d s\right.
$$

where the aggregate financial wealth of domestic consumers is made up of their holdings of money, domestic bonds and foreign bonds, $A_{t}=M_{t}+D_{t}+F_{t}{ }^{*}$.

The relationship between aggregate per capita leisure and the real wage is given by,

$$
\frac{W_{t}}{P_{t}}\left(1-N_{t}\right)=\kappa c_{t}
$$

While the money demand equation is given by,

$$
\frac{M_{t}}{P_{t}}=\chi \frac{c_{t}}{R_{t}}
$$

In the foreign country there will be corresponding equations for labour supply, money demand and consumption.

\section{The Firm's Problem:}

Given the CES form of individuals' utility, integrating the demand for good $z$ across consumers and assuming that each government allocates its spending in the same pattern as its consumers implies that world demand for product $\mathrm{z}$ is given by, 


$$
y(z)_{t}=\left(\frac{p(z)_{t}}{P_{t}}\right)^{-\theta}\left(c_{t}+c_{t}^{*}+g_{t}+g_{t}^{*}\right)
$$

where $\mathrm{y}(\mathrm{z}), \mathrm{c}, \mathrm{c}^{*}, \mathrm{~g}$, and $\mathrm{g}^{*}$ are defined as real per capita variables. Assuming a linear production function, the firm's (per capita) demand for labour will be equivalent to equation (13).

It is assumed that firms are subject to the constraints implied by Calvo (1983) contracts such that at each point in time firms are only able to change prices with probability $\alpha$. Suppose the firm is able to change at this point in time, then its objective function for determining that optimal price is given by,

$$
V(z)_{t}=\int_{t}^{\infty}\left[\left(\frac{p(z)_{t}}{P_{s}}-\frac{W_{s}}{P_{s}}\right)\left(\frac{p(z)_{t}}{P_{s}}\right)^{-\theta}\left(c_{s}+c_{s}^{*}+g_{s}+g_{s}^{*}\right)\right]\left(\exp \left(-\int_{t}^{s}\left(r_{\mu}+\alpha\right) d \mu\right) d s\right.
$$

where the discount rate is raised by the instantaneous probability $\alpha$ to reflect the fact that this price may be in force for some time.

The optimal price implied by the maximisation of this objective function is therefore given by,

$$
p(z)_{t}=\frac{\int_{t}^{\infty} \theta\left(\frac{1}{P_{s}}\right)^{1-\theta} W_{s}\left(c_{s}+g_{s}+c_{s}^{*}+g_{s}^{*}\right) \exp \left(-\int_{t}^{s}\left(r_{\mu}+\alpha\right) d \mu\right) d s}{\int_{t}^{\infty}(\theta-1)\left(\frac{1}{P_{s}}\right)^{1-\theta}\left(c_{s}+g_{s}+c_{s}^{*}+g_{s}^{*}\right) \exp \left(-\int_{t}^{s}\left(r_{\mu}+\alpha\right) d \mu\right) d s}
$$

The home output price index, $p(h)_{t}$ is a weighted average of the prices set in the past, where the weights reflect the probability that these prices are still in existence,

$$
p(h)_{t}=\left[\int_{-\infty}^{t} \alpha \tilde{p}_{s}^{1-\theta} \exp (-\alpha(t-s)) d s\right]^{\frac{1}{1-\theta}}
$$

where $\tilde{p}_{t}$ is the price set in accordance with equation (15) by those home producers that were able to change prices at that point in time. The aggregate consumer price level is, in turn, given by,

$$
P_{t}=\left[n p(h)_{t}^{1-\theta}+(1-n)\left(\varepsilon_{t} p(f)_{t}\right)^{1-\theta}\right]^{\frac{1}{1-\theta}}
$$

\section{The Government}

The home government's budget constraint is given by,

$$
d l_{t}=\left(r_{t}-\lambda\left(\pi_{t}-\pi_{t}^{e}\right)\right)\left(l_{t}-m_{t}\right)-\pi_{t} m_{t}+g_{t}-\tau_{t}
$$


where the total liabilities of the government, 1 are made of government bonds held by home consumers $\left(\mathrm{d}_{t}\right)$ or by foreign consumers $\left(f_{t}^{*}\right)$, and non-interest bearing money, $\mathrm{m}$. Aside from borrowing and seigniorage, the government finances spending by taxing levying a lumpsum tax of $\tau_{t}$ of home consumers. Assuming that all government liabilities are denominated in domestic currency, there can be a surprise deflation of debt to the extent to which debt is indexed to domestic consumer price inflation.

While the foreign government's budget constraint is given by,

$$
d l_{t}^{*}=\left(r_{t}-\lambda^{*}\left(\pi_{t}^{*}-\pi_{t}^{* e}\right)\right)\left(l_{t}^{*}-m_{t}^{*}\right)-\pi_{t}^{*} m_{t}^{*}+g_{t}^{*}-\tau_{t}^{*}
$$

\section{$\underline{\text { 2.Compatibility Between Monetary and Fiscal Policy. }}$}

In order to analyse the interactions between monetary and fiscal policy it is useful to loglinearise the model (see Appendix 1), before introducing the description of monetary and fiscal policy. We assume that the monetary policy of the both economies involves setting real interest rates to target domestic output price inflation ${ }^{8}$ so that,

$$
\vec{r} \hat{r}_{t}=(1+m) \hat{\pi}(h)_{t}-\hat{\pi}_{t}
$$

and,

$$
\vec{r}_{t}^{*}=\left(1+m^{*}\right) \hat{\pi}(f)_{t}-\hat{\pi}_{t}^{*}
$$

where a 'hatted' variable denotes the log-linearised variable.

Due to the equality of real rates across the economies and the existence of PPP in consumer prices, the UIP condition can be written as,

$$
\begin{aligned}
d \hat{\varepsilon}_{t} & =r \hat{r}_{t}+\hat{\pi}_{t}-\left(\overrightarrow{r r_{t}^{*}}+\hat{\pi}_{t}^{*}\right) \\
& =(1+m) \hat{\pi}(h)_{t}-\left(1+m^{*}\right) \hat{\pi}(f)_{t}
\end{aligned}
$$

By using the definition of consumer price inflation, we can also rewrite the monetary policy rules as,

$$
\begin{aligned}
\hat{r}_{t} & =(1+m) \hat{\pi}(h)_{t}-\left(\frac{1}{2} \hat{\pi}(h)_{t}+\frac{1}{2} \hat{\pi}(f)_{t}+\frac{1}{2} d \hat{\varepsilon}_{t}\right) \\
& =\frac{1}{2} m \hat{\pi}(h)_{t}+\frac{1}{2} m^{*} \hat{\pi}(f)_{t}
\end{aligned}
$$

We assume that fiscal policy acts to stabilise the liabilities of each fiscal authority independently, and we follow Sims (1997) in formulating a simple rule as follows,

$$
\tau_{t}=\phi_{o}+\phi_{1} l_{t}
$$

\footnotetext{
${ }^{8}$ An alternative would be to target consumer price inflation. However, work by Clarida et al (2001) suggests that targeting domestic inflation is optimal in models where the main friction is in domestic
} 
This rule can be log-linearised as,

$$
\hat{\tau}_{t}=\phi_{1} \frac{\bar{\tau}-\bar{g}}{\bar{r} \tau} \hat{l}_{t}
$$

in the home economy and,

$$
\hat{\tau}_{t}^{*}=\phi_{1}^{*} \frac{\bar{\tau}-\bar{g}}{\bar{r} \tau} \hat{l}_{t}^{*}
$$

in the foreign economy.

\section{Necessary Conditions for Saddle -Path Stability:}

In our model, it is not possible to a priori divide policy into 'Ricardian' or 'nonRicardian' regimes since at all points in time monetary and fiscal policy jointly determine the values of real and nominal magnitudes in our economies. However we can examine the conditions under which various monetary and fiscal policy combinations can deliver saddlepath stability. In other words we can identify the conditions under which policy will generate a unique path for prices under rational expectations and ensure that both countries' stocks of financial assets and liabilities return to their steady-state values following a temporary shock.

To undertake this stability analysis it is helpful to represent our economies as a dynamic system in matrix algebra form. This can be achieved quite easily as follows. First of all, note that the global market clearing conditions allow us to eliminate one of our financial asset/liability variables from the system described in Appendix 1, since it is determined as a residual of the other three. We choose to drop $\hat{a}_{t}^{*}$, although the choice is immaterial. Similarly we can eliminate $\hat{y}_{t}^{*}$ from all equations using the condition for market clearing in the goods market. Finally, noting that the definition of consumer prices implies that $\widehat{P}_{t}=\frac{1}{2} \widehat{p}(h)_{t}+\frac{1}{2} \widehat{p}(f)_{t}+\frac{1}{2} \hat{\varepsilon}_{t}$ it can be seen that home firm output (66) depends upon aggregate demand and the real exchange rate, which can be defined as, $\hat{e}_{t}=-\hat{p}(h)_{t}+\hat{p}(f)_{t}+\hat{\varepsilon}_{t}$. Therefore, any terms in domestic output can be replaced with a combination of the real exchange rate and the components of aggregate demand, $\hat{c}_{t}, \hat{c}_{t}^{*}, \hat{g}_{t}$ and $\hat{g}_{t}^{*}$, although we also need to add an equation describing the evolution of the real exchange rate,

$$
d \hat{e}_{t}=-\hat{\pi}(h)_{t}+\hat{\pi}(f)_{t}+d \hat{\varepsilon}_{t}
$$


This can then be rewritten using the UIP condition, to give,

$$
d \hat{e}_{t}=-m^{*} \hat{\pi}(f)_{t}+m \hat{\pi}(h)_{t}
$$

By adding the description of policy outlined above, we can represent the two economies in matrix form as follows,

$$
\left[\begin{array}{c}
d \hat{\pi}(h)_{t} \\
d \hat{\pi}(f)_{t} \\
d \hat{e}_{t} \\
d \hat{c}_{t} \\
d \hat{c}_{t}^{*} \\
d \hat{l}_{t}^{*} \\
d \hat{l}_{t}^{*} \\
d \hat{a}_{t}^{*}
\end{array}\right]=\left[\begin{array}{cccccccc}
\bar{r} & 0 & -\frac{1}{2} a\left(1+\frac{\bar{N}}{1-\bar{N}} \theta\right) & -a\left(1+\frac{1}{2} \frac{\bar{N}}{1-\bar{N}} \frac{\bar{c}}{\bar{y}}\right) & -\frac{\bar{N}}{1-\bar{N}} \frac{\bar{c}}{\bar{y}} \frac{a}{2} & 0 & 0 & 0 \\
0 & \bar{r} & \frac{1}{2} a\left(1+\frac{\bar{N}}{1-\bar{N}} \theta\right) & -\frac{\bar{N}}{1-\bar{N}} \frac{\bar{c}}{\bar{y}} \frac{a}{2} & -a\left(1+\frac{1}{2} \frac{\bar{N}}{1-\bar{N}} \frac{\bar{c}}{\bar{y}}\right) & 0 & 0 & 0 \\
m & -m^{*} & 0 & 0 & 0 & 0 & 0 & 0 \\
\frac{1}{2} m & \frac{1}{2} m^{*} & 0 & \bar{r}+k-v(1+\chi) & 0 & 0 & 0 & -z \\
\frac{1}{2} m & \frac{1}{2} m^{*} & 0 & 0 & \bar{r}+k-v(1+\chi) & -z & -z & z \\
\frac{1}{2} m & \frac{1}{2} m^{*} & 0 & -\frac{\chi \overline{r c}}{x} & -\frac{\chi \overline{r c}}{x} & \bar{r}-\phi_{1} & 0 & 0 \\
\frac{1}{2} m & \frac{1}{2} m^{*} & 0 & -\frac{\chi \overline{r c}}{x} & -\frac{\chi \overline{r c}}{x} & 0 & \bar{r}-\phi_{1}^{*} & 0 \\
\frac{1}{2} m & \frac{1}{2} m^{*} & \frac{r \theta \bar{y}}{2 x} & -\frac{(1+\chi) \frac{r c}{x}}{x}+\frac{\overline{r c}}{2 x} & \frac{\overline{r c}}{2 x} & -\phi_{1} & 0 & \bar{r} \\
\bar{\pi} & & & & & &
\end{array}\right]\left[\begin{array}{c}
\hat{\pi}(h)_{t} \\
\hat{\pi}(f)_{t} \\
\hat{e}_{t} \\
\hat{c}_{t} \\
\hat{c}_{t}^{*} \\
\hat{l}_{t} \\
\hat{l}_{t}^{*} \\
\hat{a}_{t}^{*}
\end{array}\right]
$$

where $a=\alpha(\alpha+\bar{r}), v=k+\sigma, z=k(k+\sigma) \frac{\bar{\tau}-\bar{g}+\chi \bar{c}}{\overline{r c}}$ and $x=\bar{\tau}-\bar{g}+\chi \bar{c}$.

The constraints on policy required to ensure a dynamically stable economy are clearer if we assume that the economy approaches its cashless limit $^{9}$ (as in Woodford (1998)) i.e. $\chi \rightarrow 0$. This has the implication that the central bank retains control over nominal interest rates, but that the contribution of seigniorage revenues to government finances are negligible. Woodford (op. cit.) shows that this cashless economy retains the essential features of the FTPL and this is confirmed for a closed economy with sticky prices and non-Ricardian consumers in Leith and Wren-Lewis (2000).

The determinant of the transition matrix of our two country model is given by,

$$
-\frac{\bar{r}}{2\left(\frac{\bar{\tau}-\bar{g}}{\bar{y}}\right)} a \overbrace{\left[\begin{array}{c}
-z\left(1+\frac{\bar{N}}{1-\bar{N}} \theta\right)\left(1-\frac{\bar{g}}{\bar{y}}\right)-z \theta \\
+(\bar{r}-\sigma) \frac{\bar{\tau}-\bar{g}}{\bar{y}}\left(1+\frac{\bar{N}}{1-\bar{N}} \theta\right)
\end{array}\right]}^{(i)} \overbrace{\left[\begin{array}{l}
m m^{*} a\left(1+\frac{\bar{N}}{1-\bar{N}}-\frac{\bar{N}}{1-\bar{N}} \frac{\bar{g}}{\bar{y}}\right)\left(-2\left(\phi_{1}-\bar{r}\right)\left(\phi_{1}{ }^{*}-\bar{r}\right)+\left(\phi_{1}+\phi_{1}{ }^{*}-2 \bar{r}\right) z\right) \\
-\left(m+m^{*}\right) \bar{r}\left(\phi_{1}-\bar{r}\right)\left(\phi_{1}{ }^{*}-\bar{r}\right)(\bar{r}-\sigma)
\end{array}\right]}^{(i i)}
$$

A necessary condition for stability is that the determinant of this matrix be negative, since we require three eigenvalues with negative real parts (corresponding to the pre-determined

\footnotetext{
${ }^{9}$ Even if we allowed for seigniorage revenues, for plausible values of $\chi$ the stability conditions shown here are not materially affected. These more complex conditions are available from the authors upon request. The numerical analysis that follows this section allows for non-zero values of $\chi$.
} 
variables $^{10}, \hat{a}_{t}, \hat{l}_{t}$ and $\hat{l}_{t}^{*}$ ) and five eigenvalues with positive real parts relating to the 'jump' variables in the system $\left(\hat{e}_{t}, \hat{\pi}(h)_{t}, \hat{\pi}(f)_{t}, \hat{c}_{t}^{*}\right.$, and $\left.\hat{c}_{t}\right)$.

The first thing to note is that the expression within the square brackets labelled (i), is unambiguously negative and does not contain any of the parameters within the policy rules ${ }^{11}$. Therefore in assessing the determinant condition for stability we need only consider the expression within the second square brackets, labelled (ii), which must be negative as a necessary condition for saddlepath stability. In this context saddlepath stability implies that all variables in the system will return to the steady-state following a temporary fiscal shock - on plausibility and welfare grounds, we do not consider the possibility of one government indefinitely accumulating the debt of the other.

The key condition can be written as

$$
\begin{aligned}
& m m^{*} a\left(1+\frac{\bar{N}}{1-\bar{N}}-\frac{\bar{N}}{1-\bar{N}} \frac{\bar{g}}{\bar{y}}\right)\left(-2\left(\phi_{1}^{*}-\bar{r}\right)\left(\phi_{1}^{*}-\bar{r}\right)+\left(\phi_{1}^{*}+\phi_{1}^{*}-2 \bar{r}\right) z<\right. \\
& \left(m+m^{*}\right)\left(\phi_{1}^{*}-\bar{r}\right)\left(\phi_{1}^{*}-\bar{r}\right) \bar{r}(\bar{r}-\sigma)
\end{aligned}
$$

where ' $a$ ' and ' $z$ ' are defined above, and are always positive. The inequality involves all four policy parameters. The term in $\left(\phi_{1}{ }^{*}+\phi_{1}{ }^{*}-2 \bar{r}\right)$ introduces the possibility of 'compensation' between fiscal policy makers in each country, and the term in $\left(m+m^{*}\right)$ does the same for monetary policy. Note that as the probability of death tends to zero, the steady state real interest rate tends to the rate of time preference, so the last term in (47) becomes unimportant, and also $\mathrm{z}$ tends to zero, so the term involving the sum of the two fiscal parameters drops out. This shows that the possibility of compensation between policy makers in different countries arises because consumers are non-Ricardian, so that changes in debt have macroeconomic demand effects which spill over from one country to another.

We can rewrite this inequality as two sets of inequalities which are conditional on various combinations of policy parameters as follows,

\footnotetext{
${ }^{10}$ It should be noted that the initial values of real government liabilities and private sector assets, may be influenced by any surprise inflation if they are denominated in nominal terms. However, since they are not themselves free to jump to any level to eliminate the influence of unstable eigenvalues on the dynamic system they should not be considered to be 'jump' variables.

${ }^{11}$ To do so substitute the expression for the equilibrium real interest rate, equation (51) into (i) and rearrange to give,$$
-z\left(1+\frac{\bar{N}}{1-\bar{N}} \theta\right)\left(1-\frac{\bar{g}}{\bar{y}}\right)+(\bar{r}-\sigma) \frac{\bar{\tau}-\bar{g}}{\bar{y}}\left(1+\frac{\bar{N}}{1-\bar{N}} \theta\right)-z \theta
$$$$
=-2 \frac{(k+\sigma) k(\bar{\tau}-\bar{g})\left[\left(\left(1+\frac{\bar{N}}{1-\bar{N}}\right) \theta+1\right) \bar{y}-\bar{\tau}\left(1+\frac{\bar{N}}{1-\bar{N}} \theta\right)\right]}{\bar{y}\left[(\bar{y}-\bar{g}) \sigma+\sqrt{(\bar{y}-\bar{g})\left(\sigma^{2}(\bar{y}-\bar{g})+4 k(k+\sigma)(\bar{\tau}-\bar{g})\right.}\right]}<0
$$ 
and,

$$
\begin{gathered}
\left(\frac{1}{\phi_{1}-\bar{r}}+\frac{1}{\phi_{1}^{*}-\bar{r}}\right)-2<2 \frac{\left(\frac{1}{m}+\frac{1}{m^{*}}\right) \bar{r}(\bar{r}-\sigma)}{\alpha(\alpha+\bar{r})\left(1+\frac{\bar{N}}{1-\bar{N}}-\frac{\bar{N}}{1-\bar{N}} \frac{\bar{g}}{\bar{y}}\right)} \\
m m^{*}>(<) 0 \text { and }\left(\phi_{1}-\bar{r}\right)\left(\phi_{1}^{*}-\bar{r}\right)>(<) 0
\end{gathered}
$$

$$
\begin{gathered}
\left(\frac{1}{\phi_{1}-\bar{r}}+\frac{1}{\phi_{1}^{*}-\bar{r}}\right)-2>2 \frac{\left(\frac{1}{m}+\frac{1}{m^{*}}\right) \bar{r}(\bar{r}-\sigma)}{\alpha(\alpha+\bar{r})\left(1+\frac{\bar{N}}{1-\bar{N}}-\frac{\bar{N}}{1-\bar{N}} \frac{\bar{g}}{\bar{y}}\right)} \\
m m^{*}>(<) 0 \text { and }\left(\phi_{1}-\bar{r}\right)\left(\phi_{1}^{*}-\bar{r}\right)<(>) 0
\end{gathered}
$$

The first set of inequalities defines a mix of policy regimes analogous to Leeper's (1991) active/passive characterisation of monetary/fiscal policy, but extended to the case of two countries operating under flexible exchange rates. Note that as the probability of death tends to zero, only the first set of inequalities is possible. The second inequality only arises with non-Ricardian consumers. Accordingly, the second set of inequalities can be thought of as 'corrections' to these definitions which apply when consumers are non-Ricardian. To see the various policy regimes these inequalities imply more clearly it is helpful to represent them diagrammatically as in Figure 1.

The two hyperbola trace out the combinations of fiscal policy parameters for which the expression labelled (ii) is zero, conditional on the values the structural parameters and on the monetary policy parameters ${ }^{12}$. The axes correspond to $\phi_{1}-\bar{r}$ and $\phi_{1}^{*}-\bar{r}$, the two fiscal policy parameters, and the various zones imply the combinations of $m m^{*}$ that are required to ensure stability. The shaded areas shows those zones implied by the first inequality, (30), while the non-shaded zones are those which exist only because consumers are non-Ricardian (the second inequality, (31)).

${ }^{12}$ Here we have assumed that the asymptotes of these hyperbole,

$$
\frac{k(k+\sigma) \frac{\bar{\tau}-\bar{g}}{\overline{r c}} \alpha(\alpha+\bar{r})\left(1+\frac{\bar{N}}{1-\bar{N}}-\frac{\bar{N}}{1-\bar{N}} \frac{\bar{g}}{\bar{y}}\right)}{2 \alpha(\alpha+\bar{r})\left(1+\frac{\bar{N}}{1-\bar{N}}-\frac{\bar{N}}{1-\bar{N}} \frac{\bar{g}}{\bar{y}}\right)+\left(\frac{1}{m}+\frac{1}{m^{*}}\right) \bar{r}(\bar{r}-\sigma)}
$$

are positive, which seems likely, although the analysis below is not significantly altered if the opposite is true. 


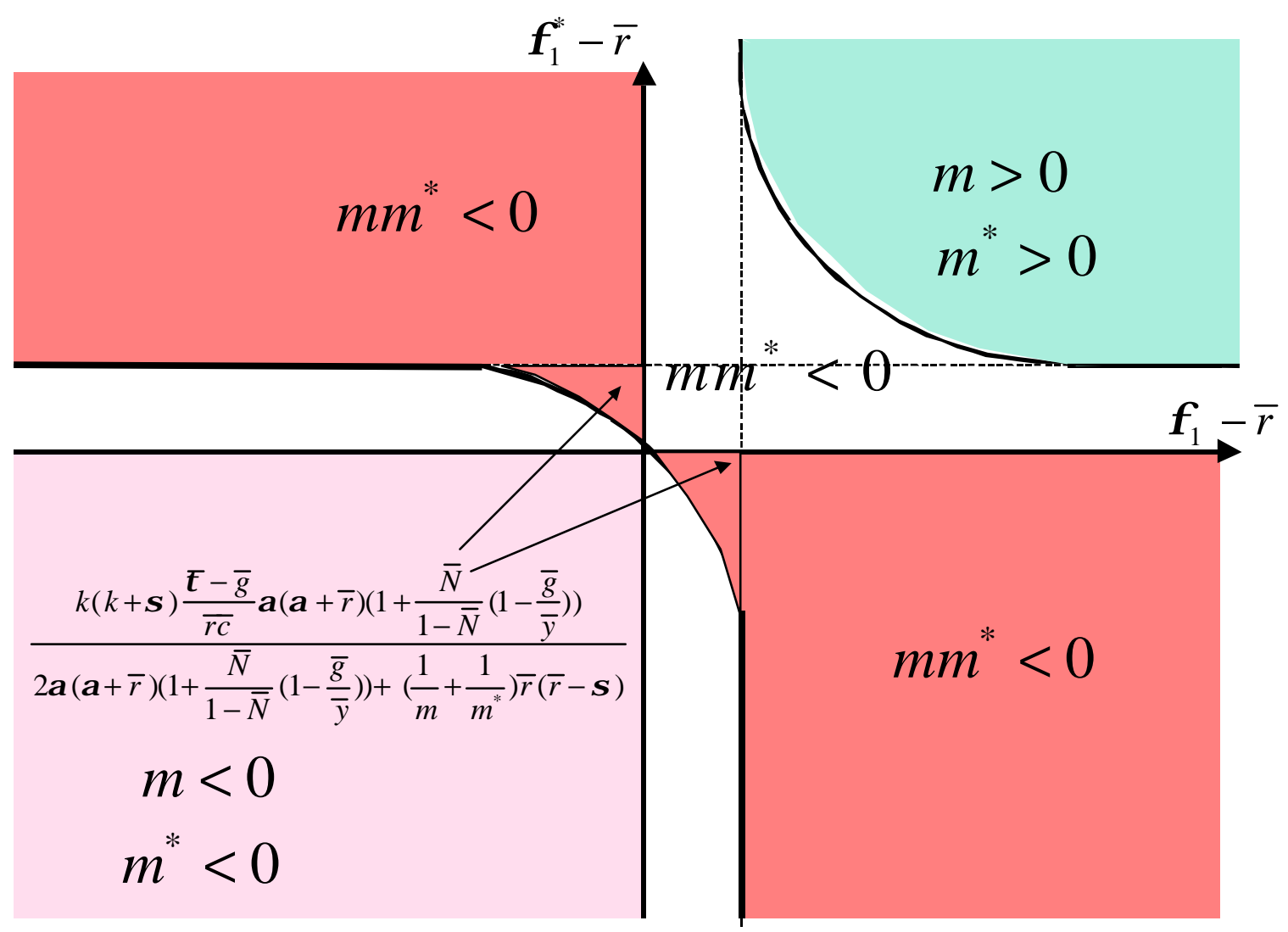

Consider the case where both fiscal authorities pursue strong debt stabilisation, so both $\phi_{1}-\bar{r}$ and $\phi_{1}^{*}-\bar{r}$ are large and positive. In this case, from the inequalities in (30), $\mathrm{mm}^{*}$ must be positive. Although the inequality can hold if both $m$ and $m^{*}$ were negative, we have found from examining eigenvalues under plausible parameter values that this combination is never stable. (Recall that (29) is a necessary, but not sufficient, condition for stability.) Thus in this case both monetary authorities have to be active. This is the counterpart to Ricardian policy regimes in the Fiscal Theory of the Price Level, and the active policy regime in Leith and Wren-Lewis (2000). As the probability of death rises, the hyperbola defining this zone shifts to the Northeast. This shows how non-Ricardian consumers increase the required degree of fiscal feedback.

The intuition behind this last result is straightforward. Consider a positive debt shock in one country. With Ricardian consumers, we simply require fiscal feedback to be marginally more than the steady state (=actual) real interest rate to prevent a debt interest spiral (see Sims, 1999). However, with non-Ricardian consumers, higher debt generates additional demand, putting upward pressure on inflation in both countries. With active monetary policy, this raises real interest rates in both countries. We have a debt interest spiral which is intensified by non-Ricardian consumers generating higher real interest rates. For stability, 
fiscal feedback must now reduce debt by significantly more than the steady state real interest rate, because actual real rates are above steady state levels.

The hyperbola in the Northeast quadrant also implies that there is some scope for a fiscal authority in one country to 'compensate' for a relatively weak fiscal response in another country and thereby enable both monetary authorities to pursue an active inflation-targeting monetary policy. However, such compensation is only feasible to the extent that both fiscal authorities operate in the shaded area in the Northeast quadrant.

Staying with the first inequality in (30), we can see that if just one fiscal authority conducts weak or no debt stabilisation (e.g. $\phi_{1}<\bar{r}$ ), then stability requires one monetary policy to be passive (i.e. $m<0$ or $m^{*}<0$ ). These are the shaded zones in the Northwest or Southeast quadrants, and correspond to a mixed Ricardian/non-Ricardian regime. Lack of fiscal feedback in one country is compensated for by a passive monetary policy in one country. In effect, monetary policy in one country acts to neutralise the potentially unstable debt-interest spiral created by lack of fiscal feedback. Again consider a positive debt shock in one country. This will generate higher inflation, and a debt-interest spiral. However if one monetary policy maker is passive, higher inflation will lead to lower real interest rates, counteracting the debt-interest spiral.

An important feature of this result is that the passive monetary policy does not need to occur in the same country as the weak fiscal feedback. In (30), $\phi_{1}<\bar{r}$ can be stable if $m^{*}<0$ and $m>0$. The possibility that a passive monetary policy in one country can 'compensate' for lack of fiscal feedback in another is explored further in numerical simulations below.

The final possibility implied by the first inequality in (30) is that both fiscal authorities fail to stabilise debt strongly $\left(\phi_{1}<\bar{r}\right.$ and $\left.\phi_{1}^{*}<\bar{r}\right)$. This implies $\mathrm{mm}^{*}>0$. As was the case with $\phi_{1}>\bar{r}$ and $\phi_{1}^{*}>\bar{r}$, we have found from examining eigenvalues that the possibility that both $m$ and $m^{*}$ are positive in this case is always unstable, so stability requires both monetary policies to be passive. In other words, this quadrant is equivalent to a non-Ricardian regime in both countries.

As consumers become almost Ricardian, these four zones tend to become identical to the four quadrants. The second inequality (31) arises because consumers are non-Ricardian, and is delineated by the non-shaded areas in the diagram. Consider the non-shaded area in the Northeast quadrant first. Here, although both fiscal feedback parameters, $\phi_{1}$ and $\phi_{1}^{*}$, exceed the steady-state real rate of interest, they are insufficiently large to prevent a debt interest spiral emerging when debt constitutes an element of net wealth due to existence of nonRicardian consumers. As a result, one monetary policy must be passive. Thus the mixed 
regime analysed above for fiscal feedback parameters of opposite sign is extended into areas where both $\phi_{1}$ and $\phi_{1}^{*}$ parameters are positive but small.

The final case occurs in the non-shaded areas of the Northwest and Southeast quadrants. Here one fiscal parameter can be very negative, but the other fiscal parameter is small but positive. In this case both $m$ parameters must be of the same sign, and numerical analysis suggest they must both be negative. Thus this area extends the rectangle in the Southwest quadrant into a hyperbolic region which is the 'reflection' of the hyperbola in the Northeast quadrant.

In summary we can identify three basic regimes which describe feasible combinations of monetary and fiscal policy. In the first regime, both fiscal authorities respond strongly to debt disequilibrium and this allows the monetary authority in each economy to actively target inflation. In the second regime, one fiscal authority continues to implement a sustainable fiscal policy, while the other does not seek to stabilise its outstanding stock of liabilities sufficiently strongly to prevent a debt interest spiral in the absence of an accommodating monetary policy. An important feature of this regime is that it does not matter which monetary authority abandons the active targeting of inflation in order to stabilise the debt of a recalcitrant fiscal authority. The final regime is where neither fiscal authority acts to stabilise its debt stock, and both monetary authorities have to abandon the active targeting of inflation to stabilise the debt stocks of their respective fiscal authorities. The distinction between these regimes depends crucially on the degree of non-Ricardian behaviour on the part of consumers. The wealth affects implied by non-Ricardian consumers typically raises the degree of fiscal feedback required to stabilise the debt stock given that the monetary authorities are pursuing an active monetary policy.

\section{Calibration and Simulation of the Model:}

In order to discuss the policy implications for different degrees of fiscal rectitude under alternative monetary policies, we need to adopt parameter values for our model. We calibrate our model as a description of the US/Euro area block. We assume that a unit of time corresponds to a quarterly data period. Accordingly, the parameters we choose are given in Table 1, along with the steady-state values these imply. 
$\underline{\text { Table } 1 \text { - Parameters and Steady-State }}$

\begin{tabular}{|l|l|l|l|l|}
\hline Parameter & Value & Variable & $\begin{array}{l}\text { Steady- } \\
\text { State } \\
\text { Value }\end{array}$ & $\begin{array}{l}\text { Steady-State Value as } \\
\text { percentage of annual } \\
\text { GDP }\end{array}$ \\
\hline$\theta$ & 8 & $\bar{y}=\bar{N}$ & 0.5 & $100 \%$ \\
\hline$\sigma$ & 0.007 & $\bar{r}$ (annualised) & 0.03 & N.A. \\
\hline$k$ & 0.0092 & $\bar{h}$ & 22.5 & $1123 \%$ \\
\hline$\tau$ & 0.125 & $\bar{a}=\bar{l}$ & 1.2 & $60 \%$ \\
\hline$\alpha$ & 0.287 & $\bar{c}$ & 0.37 & $77 \%$ \\
\hline$\kappa$ & 1.136 & $\bar{g}$ & 0.115 & $23 \%$ \\
\hline$\chi$ & 0.001 & $\bar{m}$ & 0.05 & $2.7 \%$ \\
\hline
\end{tabular}

The value of the elasticity of demand facing our imperfectly competitive firms, $\theta$, comes from the econometric work of Rotemberg and Woodford (1998). The continuously compounding quarterly discount rate of 0.007 is consistent with an annualised equilibrium real interest rate of $3 \%$, given the mark-up implied by non-Ricardian consumers. The $k$ parameter is the probability of death for our consumers. This value implies that consumers have an expected working life of 27 years. Although this may be thought to imply an implausible value for the probability of death, it is necessary to generate a plausible steadystate value of government debt relative to GDP (see below). $\tau$ is our basic level of income tax and is set at 0.125 which implies an average income tax rate of $25 \%$ of GDP. The $\kappa$ parameter is chosen such that, in steady-state, households devote, on average, $50 \%$ of their waking hours to leisure and $50 \%$ to working. While the parameter $\alpha$ measures the instantaneous probability that a firm will be able to reset its price. Therefore, $\frac{1}{\alpha}$ measures the average length of time between price changes. A value of $\frac{1}{\alpha}=3.5$, means that it takes, on average, 10.5 months for firms to reset prices. This figure is consistent with an average of the econometric estimates of this parameter for the Euro area and the US in Gali et al (2001) and Leith and Malley (2001) ${ }^{13}$. Finally, we assume, that the parameter governing the importance of money in utility is 0.001 , implying that the stock of government liabilities issued in the form of cash or deposits is $2.7 \%$ of GDP. Again these figures are consistent with the Euro area at the end of 2000 (ECB (2001)) and are not out of line with data for the US. This

\footnotetext{
${ }^{13}$ An interesting area for future research would be to consider the implications for asymmetries in the two economies, especially differing degrees of nominal inertia.
} 
parameterisation, therefore allows a small role for seigniorage revenues in the analysis that follows.

The steady-state these parameters imply is shown in the right-hand-side of the table. The real interest rate has an annualised value of around 3\%, and the steady-state ratio of debt to GDP is around 60\%, which is consistent with figures for the US (US Govt (2002)) and Euro area (ECB (2002)) economies. The ratio of government spending to GDP of just under $25 \%$ is also typical of both European and the US economy if you eliminate transfers from the definition of government spending to be left with government consumption as defined in our model (see Gali (1994), for a comparison of this ratio across OECD economies). In conducting our simulation analysis we also need to make assumptions about the composition of the initial stocks of public sector liabilities/private sector assets. Initially, we assume that all government debt is nominal, is denominated in the currency of the respective fiscal authority and that $21 \%$ of that debt is held abroad. This is line with the composition of government debt in the US where very little debt is denominated in foreign currency and the extent of indexation of the outstanding debt stock is similarly insignificant, and is not an unreasonable description of the Euro-area economy ${ }^{14}$. However, in the simulations that follow we analyse the implications of relaxing these assumptions.

We can now consider the implications of our stability analysis given the assumed parameters of our model in the case where both monetary authorities actively target inflation with a common coefficient on excess inflation in the two countries' interest rate rules of $m=m^{*}=0.5$ (as suggested in Taylor (1993)). The parameter values suggest that if both fiscal authorities ran policies such that $\phi_{1}>0.0079$ and $\phi_{1}^{*}>0.0079$ (i.e. for every one Dollar of debt disequilibrium taxes have to adjust by at least 0.0079 Dollars) then the monetary authorities would be free to actively target inflation. If one fiscal authority failed to meet this level of fiscal feedback then the other may be able to compensate for their behaviour, although only in the range of $0.0077<\phi_{1}^{*}<0.0079$, such that the monetary authorities could still run an active monetary policy. In other words, although there is the theoretical possibility of one fiscal authority compensating for the lax fiscal behaviour of another, the range over which this is possible is very small, and could require a very large fiscal response on the part of the compensating authority. Since the minimum degree of fiscal feedback required of each authority is relatively low it seems far more likely that the only sustainable policy space is where both fiscal authorities act to fulfil this condition leaving the monetary authorities free to target inflation.

\footnotetext{
${ }^{14} 34 \%$ of Euro area debt is held abroad, (ECB (2002)) but that includes intra-European holdings so that the US figure of $21 \%$ debt held abroad (US Govt (2002)) does not appear to be unreasonable.
} 


\section{Simulations:}

In this section we analyse the paths of aggregate variables in our two economies in the face of shocks under various descriptions of policy. The shock we consider is a fiscal shock which raises the real value of debt by $10 \%$, cet. par.

Initially, we assume that policy makers behave symmetrically in both economies with, $m=m^{*}=0.5$ in line with the standard parameterisation of Taylor-type rules (see Taylor (1993)) and $\phi_{1}=\phi_{1}^{*}=0.1$. This description of fiscal policy implies that each fiscal authority raises taxation by 0.1 Dollar for every 1 Dollar of debt disequilibrium. Simulating our two-economy model with these policy rules, suggests that although consumers are nonRicardian, and discount the future far more heavily than an infinitely-lived consumer would, the fiscal shock still has a negligible impact on consumption and inflation due to the active response of monetary policy. The initial (and greatest) impact on inflation in both economies is only $0.008 \%$, with consumption only rising by $0.005 \%$. The small inflation response to the fiscal shock means that surprise inflation has a very limited impact on the stock of outstanding liabilities and so whether debt is real or nominal is relatively unimportant.

We can then contrast these simulations with an example where country 1 operates an active monetary policy, $m=0.5$ alongside a fiscal policy which seeks to stabilise the real debt stock, $\phi_{1}=0.1$, while the monetary authorities in country 2 are forced to abandon their active monetary policy, $m^{*}=-0.5$ in order to compensate for the refusal of their fiscal authorities to adjust tax revenues in order to stabilise the debt stock, $\phi_{1}^{*}=0$. Figure 2 reveals the paths for the same set of variables considered above, as well as the real exchange rate, since this is no longer constant as a result of the asymmetrical policy response across the two economies, when debt is both nominal and real. Although the exchange rate is flexible and country 1 follows the same set of policies as described above, the impact of the same fiscal shock on inflation and consumption in both economies is far more significant - annualised output price inflation rises by almost $6.6 \%$ in country 2 on impact, while falling to $-2.5 \%$ in country 1 , as the asymmetry in the conduct of monetary policy generates real exchange rate changes which reduce demand and, therefore, inflation in country 1. From equation (23) we see that the net effect of monetary policy in the two economies is to reduce real interest rates (which are equalised across the two economies due to the presence of PPP) and this brings consumption forward in time, such that consumption rises by $5 \%$ and $6.3 \%$ on impact in countries 1 and 2, respectively. However, the path for consumption is higher in country 2 throughout the simulation. The reason is that the large appreciation of the real exchange rate as a result of the relatively active monetary policy in country 1 , means that, due to the 
nominal inertia in price setting, output falls in country 1 relative to consumption and consumers in country 1 are forced to borrow from abroad to maintain consumption. The converse is true in country 2. It should be noted that, in contrast to the OR model, this consumption differential will not last forever, and the economies will eventually return to the unique steady-state ${ }^{15}$.

Figure 2 also considers what happens when debt is denominated in real terms. In this case the initial jump in inflation does not serve to reduce the real value of government debt in country 2 (debt in country 1 is not deflated since the active monetary policy induces a large exchange rate appreciation which reduces consumer prices in country 1 relative to country 2) and the passive monetary policy in country 2 has to reduce real interest rates by more in order to return the debt stock to equilibrium. This increased role for the monetary authorities in Country 2 in stabilising indexed debt typically doubles the disequilibrium consquences of the fiscal shock

The next simulation we consider is where the fiscal authorities in country 2 still do not react to debt disequilibrium, $\phi_{1}^{*}=0$, but where their monetary authorities pursue an active monetary policy, $m^{*}=0.5$ In contrast the fiscal authorities in country 1 still act to stabilise their real stock of debt, $\phi_{1}=0.1$, but the monetary authorities pursue a passive monetary policy, $m=-0.5$. The paths for relevant endogenous variables are detailed in Figure 3. Here we confirm a key result in the analysis of section 2 - namely that the monetary authorities in country 1 can compensate for the lax fiscal behaviour in country 2. An important implication of this policy, revealed in the simulation, is that country 1 now suffers the higher rate of inflation as a result of their passive monetary policy. However, the real exchange rate depreciation this induces allows them to accumulate net foreign assets and maintain consumption at a higher level than their neighbours for a sustained period. The passive monetary policy in one economy acts to stabilise the debt stock in another country by reducing real interest rates in both economies. The rise in output price inflation in country 1 and the ongoing appreciation of the nominal exchange rate, feeds consumer price inflation in country 2, which will reduce real interest rates, cet. par. This, in turn, reduces debt service costs in country 2 and stabilises the debt stock. The main problem with this policy, however, is that the passive monetary policy in country 1 induces a large exchange rate depreciation which means that there is no surprise increase in consumer prices in country 2 and no initial debt deflation. Instead, the policy deflates debt in country 1 where a stabilising fiscal policy is already in place and so this is of little consequence. Accordingly, exchange rate movements

\footnotetext{
${ }^{15}$ However, our simulation results suggest that with near Ricardian behaviour on the part of consumers, this can take around 100 years in this particular case.
} 
imply that using monetary policy to deflate debt is best achieved from within the same economy.

These results suggest that a global economy made up of responsible monetary and fiscal authorities has little to fear from fiscal shocks. However, when one fiscal authority does not act to stabilise its debt stock, then there must be offsetting behaviour from a monetary policy maker to avoid an unsustainable debt interest spiral. We have shown that there is no reason for the compensating monetary policy makers to reside in the same country as the recalcitrant fiscal authorities - a foreign monetary authority can also engineer the reduction in domestic debt service costs through their influence on the import component of home country consumer prices. However, the costs of using monetary policy to stabilise debt will be greater when the debt is denominated in the currency of an active monetary authority, since this limits the size of the initial debt deflation due to offsetting exchange rate movements. Similarly, indexing the debt stocks also reduces the stabilising effects of surprise inf lation and requires a more sustained application of a passive monetary policy to stabilise debt.

\section{Conclusions}

In this paper we derived a two country open-economy model where over-lapping generations of consumers, consumed a basket of domestically and foreign-produced goods and supplied labour to the imperfectly competitive firms producing these goods. These firms were assumed to only be able to alter their prices after a random interval of time, so that monetary policy could have real short run effects. This allowed us to examine a model where the range of fiscal and monetary policy interactions were wider than normally considered in open economy extensions of the FTPL.

We identified the restrictions on fiscal policy required to support the active targeting of inflation on the part of the monetary authorities. A key result was that minimum responsiveness of tax revenues to debt disequilibrium required to support an active monetary policy was greater when consumers were non-Ricardian. Additionally if any fiscal authority did not meet this minimal requirement then there was limited scope for the other fiscal authority to compensate. In the absence of such behaviour, the monetary authorities would have to operate a passive monetary policy which offset any debt disequilibrium by reducing debt service costs. However, in a model featuring free trade, where output price inflation in one economy affects consumer prices in the other, there was no reason for the passive monetary authority to reside in the same country as the insolvent fiscal authority.

Finally, in a series of simulations we demonstrated that when all the fiscal authorities adjust taxes to stabilise their real debt stocks, then fiscal shocks will have a limited impact on macroeconomic variables such as output and inflation. In contrast, when one monetary 
authority abandons its active policy to assist an otherwise unstable fiscal authority, then the macroeconomic impact of a fiscal shock can be sizeable. The costs of such a policy are, however, lessened to the extent that initial price and exchange rate movements serve to deflate the real value of the debt of the recalcitrant fiscal authority through surprise consumer price inflation, and this is achieved when the debt is nominal and denominated in the currency of the passive monetary authority.

\section{References:}

1. Bergin, P. R. (2000), "Fiscal Solvency and Price Level Determination in a Monetary Union”, Journal of Monetary Economics, No. 45, pp37-53

2. Calvo, G. (1983), "Staggered Prices in a Utility Maximising Framework", Journal of Monetary Economics, No. 12(3), pp 383-298

3. Canzoneri, M. B., R. E. Cumby and B. T. Diba (2001), "Fiscal Discipline and Exchange Rate Systems", Economic Journal, No. 474, pp 667-690.

4. Canzoneri, M. B., R. E. Cumby and B. T. Diba (2002), "Is the Price Level Determined by the Needs of Fiscal Solvency", American Economic Review, forthcoming

5. Christiano, L. and T. Fitzgerald (2000), "Understanding the Fiscal Theory of the Price Level”, NBER Working Paper No. 7668.

6. Clarida, R., J. Gali and M. Gertler (2001), “Optimal Monetary Policy in Open Economies: An Integrated Approach", American Economic Review, Vol.91(2), pp 248-252.

7. Daniel, B. C. (2001), "The Fiscal Theory of the Price Level in an Open Economy", Journal of Monetary Economics, No. 48, pp293-308.

8. Dupor, B. (2000), "Exchange Rates and the Fiscal Theory of the Price Level”, Journal of Monetary Economics, No. 45, pp 613-630.

9. ECB (2002), "Euro Area Statistics" Monthly Bulletin, June 2002, pp1*-83*.

10. Gali, J. (1994), “Government Size and Macroeconomic Stability”, European Economic Review, No. 28, pp117-132.

11. Gali, J., M. Gertler and G. D. Lopez-Salido (2001), "European Inflation Dynamics", European Economic Review, 45, pp 1237-1270.

12. Leeper, E. M. (1991), “Equilibria under 'Active' and 'Passive' Fiscal Policies”. Journal of Monetary Economics, No. 27, pp 129-147.

13. Leith, C. and J. Malley (2001), "Estimated General Equilibrium Models for the Evaluation of Monetary Policy in the US and Europe", University of Glasgow Discussion $\begin{array}{llll}\text { Paper No. 2001-16. Nownloadable } & \text { Nom }\end{array}$ http://www.gla.ac.uk/Acad/PolEcon/pdf01/2001_16.pdf 
14. Leith, C. and S. Wren-Lewis (2000), "Interactions Between Monetary and Fiscal Policy Rules", Economic Journal, Vol. 110, No. 462, pp 93-108.

15. Leith, C. and S. Wren-Lewis (2001), "Compatability Between Monetary and Fiscal Policy Under EMU", University of Glasgow, Discussion Paper no. 2001-17. Downloadable from http://www.gla.ac.uk/Acad/PolEcon/pdf01/2001_17.pdf

16. Leith, C. and S. Wren-Lewis (2002), "Taylor Rules in the Open Economy", University of Glasgow, mimeo.

17. Loyo, E. (1997), "Going International with the Fiscal Theory of the Price Level",Princeton University, mimeograph.

18. Obsfeldt, M. and K. Rogoff (1995), "Exchange Rate Dynamics Redux", Journal of Political Economy, No. 103, pp 624-660.

19. Rotemberg, J. J. and M. Woodford (1998), "An Optimization-Based Econometric Framework for the Evaluation of Monetary Policy: Expanded Version", NBER Technical Working Paper No. 233.

20. Sims, C. A. (1997), "Fiscal Foundations of Price Stability in Open Economies", Yale University, mimeograph.

21. Sims, C. A. (1999), “The Precarious Fiscal Foundations of EMU”, Yale University, mimeograph.

22. Taylor, J. (1993), "Discretion Versus Policy Rules in Practice”, Carnegie-Rochester Series on Public Policy, Vol 39, pp195-214.

23. Woodford, M. (1995), "Price-Level Determinacy Without Control of a Monetary Aggregate”, Carnegie-Rochester Conference Series on Public Policy, No. 43, pp1-53.

24. Woodford, M. (1998), "Control of the Public Debt: A Requirement for Price Stability?" in G. Calvo and M. King (eds) The Debt Burden and its Consequences for Monetary Policy, Pub. St Martin's Press, New York.

25. Woodford, M. (2001), "Fiscal Requirements for Price Stability", Journal of Money, Credit and Banking No.33: pp 669-728.

26. US Govt (2002), "Budget of the US Government”, Pub. US Government Printing Office, Washington. 


\section{Appendix 1 - Log-Linearising around the Steady-State}

Equation (15) shows that the optimal price in a zero-inflation steady-state, which is the same as that which would be set under flexible prices, is given by

$$
\bar{p}(h)=\frac{\theta}{\theta-1} \bar{W}
$$

Combining this with the labour supply condition, the linear production function and the national accounting identity (in the symmetrical steady-state the current account will be in balance so that $\bar{y}=\bar{c}+\bar{g}$ ), yields the following equilibrium output,

$$
\bar{y}=\bar{N}=\frac{\frac{\theta-1}{\theta}+\kappa \bar{g}}{\frac{\theta-1}{\theta}+\kappa}
$$

The steady-state consumption function becomes,

$$
\bar{c}=(k+\sigma)\left(\frac{(\bar{y}-\bar{\tau})}{\bar{r}+k}+\frac{\bar{D}+\bar{\varepsilon} \bar{F}}{\bar{P}}+\frac{\bar{M}}{\bar{P}}\right)
$$

The domestic government's budget constraint becomes,

$$
\frac{\bar{D}+\bar{F}^{*}}{\bar{P}}=\frac{\bar{\tau}-\bar{g}}{\bar{r}}
$$

money demand is given by,

$$
\bar{m}=\chi \frac{\bar{c}}{\bar{r}}
$$

Note that in this symmetrical equilibrium, with PPP due to free trade, it will also be the case that the real value of debt held overseas will be the same in both countries, $\frac{\bar{F}^{*}}{\bar{P}}=\frac{\bar{\varepsilon} \bar{F}}{\bar{P}}$. This fact, combined with equations (47)-(50), will determine the steady-state value of real assets in the model, along with the equilibrium real interest rate. which is given by,

$$
\bar{r}=\frac{1}{2} \frac{(\bar{y}-\bar{g}) \sigma+\sqrt{(\bar{y}-\bar{g})\left(\sigma^{2}(\bar{y}-\bar{g})+4 k(k+\sigma)(\bar{\tau}-\bar{g})\right.}}{\bar{y}-\bar{g}}
$$

Since consumers are not infinitely lived, the real interest rate is not identical to consumers' rate of time preference, but will be affected by the outstanding stock of government liabilities, since these liabilities constitute an element in consumers' net wealth.

\section{Log-Linearising the Model:}

We now proceed to log-linearise the model around the symmetrical steady-state. To illustrate this consider the labour supply equation, 


$$
w_{t}\left(1-N_{t}\right)=\kappa c_{t}
$$

Taking the natural logarithm of both sides, differentiating with respect to time and evaluating this expression at the symmetrical steady-state yields,

$$
\frac{\bar{N}}{1-\bar{N}} \hat{N}_{t}=\widehat{w}_{t}-\hat{c}_{t}
$$

Where a hatted variable denotes the percentage deviation from steady-state, $\hat{X}_{t}=\frac{\left.d X_{t}\right|_{x=\bar{x}}}{\bar{X}}$. This approach can be applied to all the equations in our model. We now focus on the derivation of the key dynamic equations in our system.

First, consider the linearised expression for the optimal price set by a home firm,

$$
\tilde{\tilde{p}}_{t}=\int_{t}^{\infty}(\bar{r}+\alpha)\left[\widehat{P}_{s}+\widehat{w}_{s}\right] \exp (-(\bar{r}+\alpha)(s-t) d s
$$

Differentiating this expression with respect to time and substituting for the definition of consumer prices, $\hat{P}_{t}=\frac{1}{2} \hat{p}(h)_{t}+\frac{1}{2} \hat{p}(f)_{t}+\frac{1}{2} \hat{\varepsilon}_{t}$, yields,

$$
d \widehat{\tilde{p}}_{t}=(\bar{r}+\alpha)\left(\tilde{\tilde{p}}_{t}-\frac{1}{2} \hat{p}(h)_{t}-\frac{1}{2} \hat{p}(f)_{t}-\frac{1}{2} \hat{\varepsilon}_{t}-\widehat{w}_{t}\right)
$$

Log-linearising the expression for the index of home country output prices gives,

$$
\left.\hat{p}(h)_{t}=\int_{-\infty}^{t} \alpha \hat{\tilde{p}}_{s} \exp (-\alpha(t-s)) d s\right]
$$

Differentiating with respect to time twice, utilising (55) and substituting the linearised labour supply function into this expression yields,

$$
d \hat{\pi}(h)_{t}=\bar{r} \hat{\pi}(h)_{t}-\alpha(\alpha+\bar{r})\left(\hat{c}_{t}+\hat{y}_{t}\right)+\alpha(\alpha+\bar{r})\left(\frac{1}{2} \hat{p}(h)_{t}-\frac{1}{2} \hat{p}(f)_{t}-\frac{1}{2} \hat{\varepsilon}_{t}\right)
$$

Now consider the domestic government's budget constraint in terms of real total government liabilities,

$$
d l_{t}=r_{t} l_{t}-\left(r_{t}+\pi_{t}\right) m_{t}+g_{t}-\tau_{t}
$$

where $l_{t}=\frac{D_{t}+F_{t}^{*}+M_{t}}{P_{t}}$. Log-linearising, utilising the definition of the steady-state and noting that with 'independent' monetary policies the fiscal authorities will only receive the seigniorage revenues generated by their own monetary authorities, gives,

$$
d \hat{l}_{t}=\hat{r}_{t}+\bar{r} \hat{r}_{t}-\frac{\chi \overline{y r}}{\bar{\tau}-\bar{g}+\chi \bar{y}} \hat{y}_{t}-\frac{\bar{\tau} \bar{r}}{\bar{\tau}-\bar{g}+\chi \bar{y}} \hat{\tau_{t}}
$$

In our open economy the evolution of private sector financial assets in the home country is given by, 


$$
d a_{t}=r_{t} a_{t}-(1+\chi) c_{t}+y_{t}-\tau_{t}
$$

which can be log-linearised as,

$$
d \hat{a}_{t}=\overrightarrow{r a} \hat{a}_{t}+\overline{r r}_{t}-(1+\chi) \frac{\overline{r c}}{\bar{\tau}-\bar{g}+\chi \bar{y}} \hat{c}_{t}+\frac{\overline{r y}}{\bar{\tau}-\bar{g}+\chi \bar{y}} \hat{y}_{t}-\frac{\bar{\tau} \bar{r}}{\bar{\tau}-\bar{g}+\chi \bar{y}} \hat{\tau}_{t}
$$

Any increase in the level of the financial wealth of the private sector relative to the liabilities of the government implies an increase in holdings of foreign government debt given the global market clearing condition in the bond market,

$$
\hat{a}_{t}+\hat{a}_{t}^{*}=\hat{l}_{t}+\hat{l}_{t}^{*}
$$

Differentiating the consumption function (10) with respect to time,

$$
d c_{t}=(k+\sigma)\left(d a_{t}+d h_{t}\right)
$$

where, human wealth is given by $h_{t}=\int_{t}^{\infty}\left(y_{s}-\tau_{s}\right) \exp \left(-\int_{t}^{s}(r(\mu)+k) d \mu\right) d s$, and $d h_{t}=\left(r_{t}+k\right) h_{t}-y_{t}+\tau_{t}$. Using the equations of motion for human and non-human wealth allows us to rewrite the equation of motion for consumption as,

$$
d c_{t}=\left(r_{t}+k-(k+\sigma)(1+\chi)\right) c_{t}-k(k+\sigma) a_{t}
$$

This can be log-linearised as,

$$
d \hat{c}_{t}=(\bar{r}+k-(k+\sigma)(1+\chi)) \hat{c}_{t}+\bar{r} \hat{r}_{t}-k(k+\sigma) \frac{\bar{\tau}-\bar{g}+\chi \bar{y}}{\overline{r c}} \hat{a}_{t}
$$

Further, since consumption is not synonymous with output in the open economy, we need to consider the definition of average firm output,

$$
\hat{y}_{t}=-\theta \hat{p}(h)_{t}+\theta \hat{P}_{t}+\frac{1}{2}\left(\frac{\bar{y}-\bar{g}}{\bar{y}}\left(\hat{c}_{t}+\hat{c}_{t}^{*}\right)+\frac{\bar{g}}{\bar{y}}\left(\hat{g}_{t}+\hat{g}_{t}^{*}\right)\right)
$$

alongside the global goods market clearing condition,

$$
\hat{y}_{t}+\hat{y}_{t}^{*}=\left(1-\frac{\bar{g}}{\bar{y}}\right)\left(\hat{c}_{t}^{*}+\hat{c}_{t}\right)+\frac{\bar{g}}{\bar{y}}\left(\hat{g}_{t}^{*}+\hat{g}_{t}\right)
$$

Similar expressions exist for the foreign economy.

Finally we have the UIP governing the dynamics of the exchange rate,

$$
d \hat{\varepsilon_{t}}=\bar{r} \hat{r}_{t}+\hat{\pi}_{t}-\left(\bar{r} \hat{r}_{t}^{*}+\hat{\pi}_{t}^{*}\right)
$$


Figure 2 - Monetary Policy in Country 2 Compensates for Insolvent Fiscal Policy in Country $\underline{2^{16}}$

Output Price Inflation

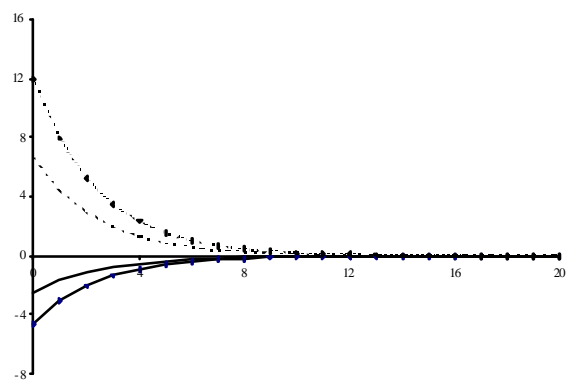

Consumption

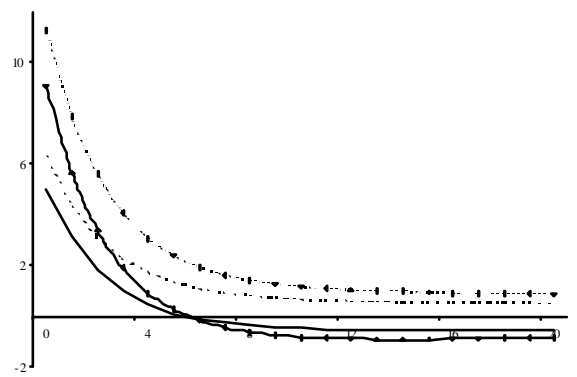

Real Exchange Rate

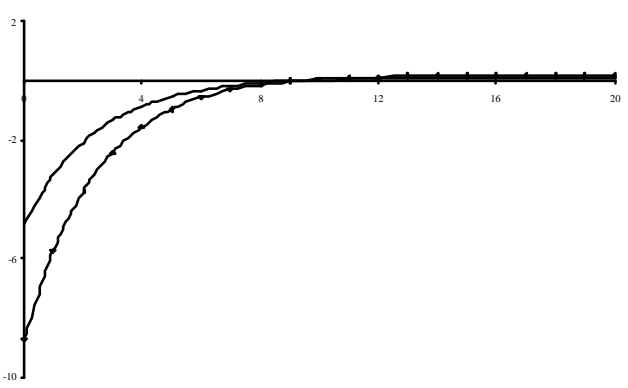

Financial Assets

Debt
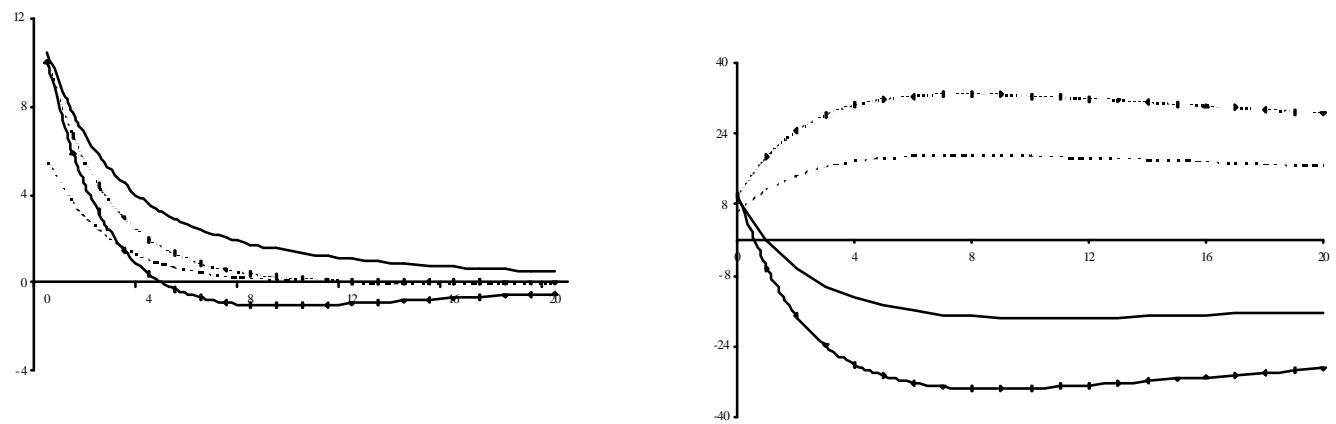

\footnotetext{
${ }^{16}$ The lines with diamonds indicate the paths of variables when government debt is indexed to each country's consumer price inflation. Lines without diamonds apply when debt is nominal. Solid lines refer to country 1 and dashed lines to country 2 .
} 
Figure 3 - Monetary Policy in Country 1 Compensates for Insolvent Fiscal Policy in Country $\underline{2}$

Output Price Inflation

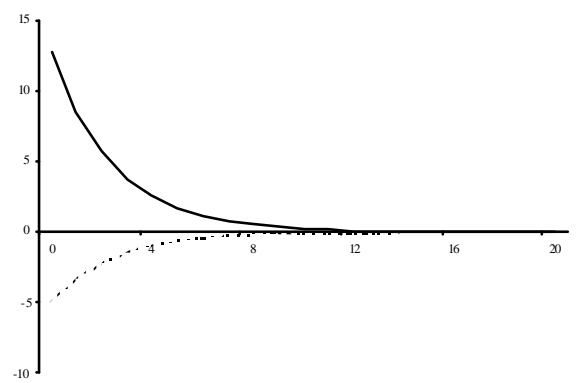

Consumption

Real Exchange Rate
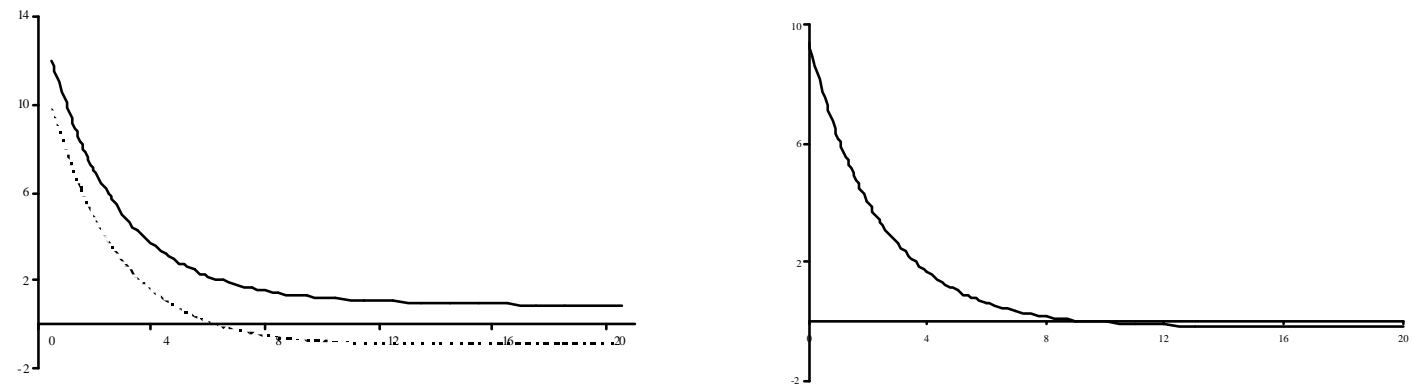

Debt

Financial Assets
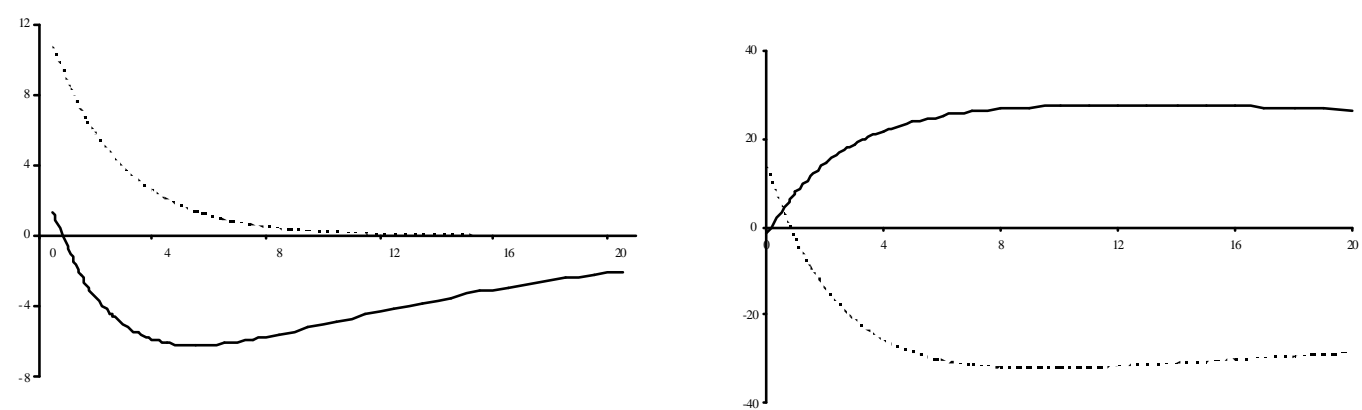